\title{
Severe Mediastinal Emphysema and Tension Pneumothorax Caused by Cough-Induced Intercostal Lung Herniation
}

\author{
Shinjiro Mizuguchi'1,2*, Masahide Kaji ${ }^{1,2}$, Toshihiko Yoshida², Takeshi Iwasaki ${ }^{3}$, \\ Takao Kamimori ${ }^{1}$, Hiroshi Fujiwara ${ }^{1}$ \\ ${ }^{1}$ Respiratory Center, Yodogawa Christian Hospital, Osaka, Japan \\ ${ }^{2}$ Department of Surgery, Yodogawa Christian Hospital, Osaka, Japan \\ ${ }^{3}$ Department of Surgery, National Hospital Organization, Kobe Medical Center, Kobe, Japan \\ Email: ${ }^{*}$ 1293795@msic.med.osaka-cu.ac.jp
}

Received 10 December 2013; revised 10 January 2014; accepted 18 January 2014

Copyright (C) 2014 by authors and Scientific Research Publishing Inc.

This work is licensed under the Creative Commons Attribution International License (CC BY). http://creativecommons.org/licenses/by/4.0/

(c) (i) Open Access

\begin{abstract}
We report a case of cough-induced intercostal lung herniation with severe mediastinal emphysema and pneumothorax. A 60-year-old overweight man was admitted with dyspnea, chest pain, and chest wall bulging. Imaging confirmed left pneumothorax, fractures of the 8th to 10th ribs, and a defect in the 8th intercostal muscles. The presence of protrusion of lung parenchyma outside the intercostal space was unclear. Although the symptoms of tension pneumothorax disappeared after drainage, the subcutaneous emphysema was uncontrollable. Emergency surgery revealed lung injury near the 8th rib wedge not directly related to the rib fracture, and lung herniation was observed. We performed direct approximation of the ribs, and the lung parenchymal surface was encased by absorbable materials, avoiding infection risk. Although the lung herniation recurred 5 months later, the patient did not desire additional surgical repair. Non-absorbable materials should be considered for repair of lung herniation, excluding patients at high infection risk.
\end{abstract}

\section{Keywords}

Intercostal Lung Herniation; Cough/Sneeze; Surgical Procedure

\section{Introduction}

Lung herniation, defined as protrusion of the lung parenchyma through a defect in the thoracic wall, is a rare

*Corresponding Author.

How to cite this paper: Mizuguchi, S., et al. (2014) Severe Mediastinal Emphysema and Tension Pneumothorax Caused by Cough-Induced Intercostal Lung Herniation. Open Journal of Thoracic Surgery, 4, 1-4.

http://dx.doi.org/10.4236/ojts.2014.41001 
event [1] [2]. Fewer than 25 cases of cough/sneeze-induced lung herniation have been reported [2]-[11]. We report a case of spontaneous intercostal pulmonary herniation following a cough, with severe mediastinal emphysema and tension pneumothorax.

\section{Case}

A 60-year-old overweight man (168 cm, $86 \mathrm{~kg}$; BMI, 30.4) was admitted to our emergency unit with severe dyspnea, left-sided chest pain, and chest wall bulging. He was a heavy smoker (80 pack-years) with a history of chronic obstructive pulmonary disease (COPD) and administration oforal steroids. Data from the previous institution revealed a forced expiratory volume in 1 second of $1.0 \mathrm{~L}$ (40.8\% of predicted) and a total lung capacity of $2.38 \mathrm{~L}$ (67.8\% of predicted). He had been treated for 10 days for severe chest pain after coughing. He had no history of chest trauma or thoracic surgery.

A chest radiograph and computed tomography (CT) confirmed left pneumothorax, fractures of the 8th to 10th ribs, and a defect of the 8th intercostal muscles. The presence of protrusion of lung tissue outside the intercostal space was unclear (Figures 1(a), (b)). Although the symptoms of tension pneumothorax disappeared after chest drainage, the chest wall bulge above the 8th intercostal space worsened and emergency surgical repair was thus performed.

A 15-cm skin incision was made over the defect in the rib line,revealing rupture of the herniation sac. The sternochondrocostal joint of the 9th rib was dislocated. A water-sealing test revealed a lung injury (15-mm length) near the 8th rib wedge (Figure 1(c)) that was not directly related to the rib fracture, and the lung herniation through the 8th intercostal space was identified by manual ventilation. These findings showed that severe mediastinal/subcutaneous emphysema and tension pneumothorax were caused by cough-induced intercostal lung herniation. Therefore, the lung parenchymal surface was encased bytriple layer of absorbable PGA felt (Neoveil $^{\circledR}$; Gunze Limited, Tokyo, Japan) before approximating the ribswith pericostal sutures using synthetic absorbable suture (Figure 1(d)). The patient discharged on day 47 after physical rehabilitation. However, the

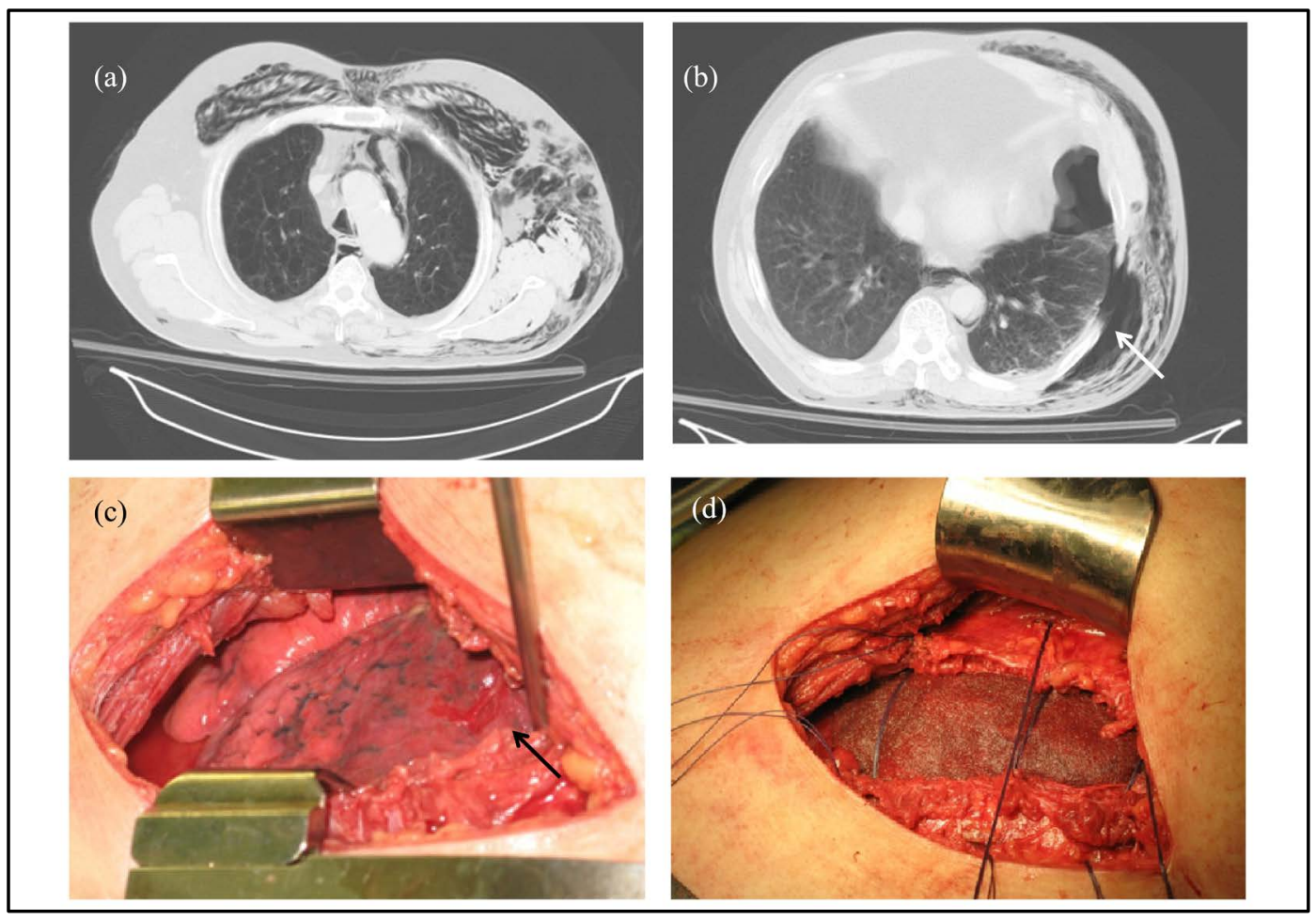

Figure 1. Computed tomography showing (a) subcutaneous/mediastinal emphysema, left pneumothorax, 8th to 10th rib fractures; (b) the defect of the 8th intercostal muscles (arrow). Intraoperative findings showing; (c) enlargement of the 8th intercostal space and lung injury near the 8th rib wedge (arrow); (d) repair of the lung herniation using absorbable materials. 
lung herniation recurred 5 months later as detected with paradoxical motion of the chest wall, which was controlled by a rib belt. The patient has been in good health and does not wish to undergo additional surgical repair.

\section{Discussion}

Lung herniation is relatively rare. Eighty percent of lung herniationsare secondary to trauma or surgery, and the remaining 20\% are congenital [3]. Brock et al. [4] had reported thatthe characteristics of spontaneous anterior lung hernias. These hernias tended to occur in male smokers with underlying pulmonary disease after coughing or sneezing episodes. The mechanism of cough/sneeze-induced lung herniation reportedly involved intercostal muscle weakness in combination with increased intrathoracic pressure [2]. Cough/sneeze-induced spontaneous lung intercostal herniation is very rare, and 23 cases have been reported in the English-language literature (Table 1). Patient ages ranged from 19 to 80 years with a median of 62 years; 23 patients were male, and only

Table 1. Cough/sneeze-induced spontaneous intercostal lung herniation.

\begin{tabular}{|c|c|c|c|c|c|c|c|c|c|c|c|c|c|c|c|c|}
\hline & Author & Year & Gender & Age & Obese & Smoker & Side & ICS & $\begin{array}{l}\text { Size } \\
(\mathrm{cm})\end{array}$ & Cause & Repair & Material & $\begin{array}{c}\text { Emergency } \\
\text { operation }\end{array}$ & $\begin{array}{c}\text { Pneumothorax/ } \\
\text { subcutaneous } \\
\text { emphysema }\end{array}$ & $\begin{array}{l}\text { Pulmonary } \\
\text { disease }\end{array}$ & $\begin{array}{c}\text { Long } \\
\text { term } \\
\text { result }\end{array}$ \\
\hline 1 & Nielsen & 1971 & M & 76 & - & - & $\mathrm{L}$ & $9 / 10$ & 30 & Cough & Primary & $\begin{array}{c}\text { non-absorbable } \\
\text { suture }\end{array}$ & No & No & pneumonia & a $\begin{array}{c}2 \\
\text { month }\end{array}$ \\
\hline 2 & Sheka & 1984 & M & - & - & - & $\mathrm{R}$ & $8 / 9$ & 15 & Cough & Primary & wire & No & No & - & 7 days \\
\hline 3 & Sloth-Nielsen & 1989 & M & 70 & - & - & $\mathrm{L}$ & $7 / 8$ & 3 & Cough & Primary & wire & No & No & COPD & - \\
\hline 4 & Scullion & 1994 & M & 60 & - & Yes & $\mathrm{R}$ & $9 / 10$ & - & Cough & - & - & No & No & COPD & - \\
\hline 5 & Sonett & 1994 & M & 52 & Yes & Yes & $\mathrm{R}$ & $7 / 8$ & 10 & Sneeze & Primary & wire & NS (yes?) & No & bronchitis & 1 month \\
\hline 6 & Sodani & 1996 & M & 80 & - & - & $\mathrm{R}$ & $6 / 7$ & - & Cough & - & - & - & No & - & - \\
\hline 7 & Folz & 1998 & M & 48 & - & Yes & $\mathrm{L}$ & $2 / 3$ & - & Cough & - & - & - & - & COPD & - \\
\hline 8 & Goverde [3] & 1998 & M & 70 & - & Yes & $\mathrm{R}$ & $8 / 9$ & - & Cough & Primary & $\begin{array}{c}\text { non-absorbable } \\
\text { suture }\end{array}$ & No & No & COPD & 2 years \\
\hline 9 & Ross [2] & 1999 & M & 55 & - & - & $\mathrm{R}$ & $7 / 8$ & - & Cough & Patch & $\begin{array}{c}\text { non-absorbable } \\
\text { mesh }\end{array}$ & No & No & COPD & - \\
\hline 10 & Brock [4] & 2000 & M & 72 & Yes & Yes & $\mathrm{L}$ & $8 / 9$ & 20 & Cough & Patch & $\begin{array}{c}\text { non-absorbable } \\
\text { mesh }\end{array}$ & No & No & COPD & $\begin{array}{c}8 \\
\text { months }\end{array}$ \\
\hline 11 & Brock [4] & 2000 & M & 44 & Yes & Yes & $\mathrm{R}$ & $8 / 9$ & 12 & Sneeze & Patch & $\begin{array}{c}\text { non-absorbable } \\
\text { mesh }\end{array}$ & No & No & - & $\begin{array}{c}8 \\
\text { months }\end{array}$ \\
\hline 12 & D. Tack [5] & 2000 & M & 62 & Yes & Yes & $\mathrm{L}$ & - & - & Cough & No & - & - & - & - & - \\
\hline 13 & Rusca & 2000 & M & 67 & - & - & $\mathrm{R}$ & $8 / 9$ & 11 & Cough & Patch & absorbable mesh & No & No & bronchitis & - \\
\hline 14 & Tamburro & 2000 & M & 19 & - & - & $\mathrm{R}$ & $9 / 10$ & - & Cough & - & - & - & - & - & - \\
\hline 15 & Ayers & 2002 & M & 68 & - & - & $\mathrm{R}$ & $7 / 8$ & - & Cough & Patch & - & No & No & asthma & 1 month \\
\hline 16 & $\begin{array}{c}\text { Szentkereszty } \\
{[6]}\end{array}$ & 2006 & M & 60 & - & - & $\mathrm{L}$ & $8 / 9$ & 30 & Cough & Primary & - & No & No & COPD & $\begin{array}{l}1 \text { year } \\
\text { rec }\end{array}$ \\
\hline 17 & $\begin{array}{c}\text { Szentkereszty } \\
{[6]}\end{array}$ & 2006 & M & 64 & - & - & $\mathrm{L}$ & $8 / 9$ & - & Cough & Patch & $\begin{array}{c}\text { non-absorbable } \\
\text { mesh }\end{array}$ & No & No & No & 5 years \\
\hline 18 & Sulaiman [7] & 2006 & M & 57 & Yes & Yes & $\mathrm{L}$ & $8 / 9$ & 10 & Cough & Primary & - & No & No & COPD & $\begin{array}{l}1 \text { year } \\
\text { rec }\end{array}$ \\
\hline 19 & $\begin{array}{c}\text { KM Jastrow } \\
{[8]}\end{array}$ & 2009 & M & 72 & Yes & Yes & $\mathrm{R}$ & $8 / 9$ & 4 & Cough & Patch & $\begin{array}{c}\text { non-absorbable } \\
\text { mesh }\end{array}$ & Yes & No & bronchitis & 5 years \\
\hline 20 & Shankar [9] & 2010 & M & 63 & - & Yes & $\mathrm{L}$ & $4 / 5$ & - & Cough & Primary & wire & Yes & No & COPD & - \\
\hline 21 & Habib & 2010 & M & 47 & Yes & Yes & $\mathrm{L}$ & $8 / 9$ & 15 & Cough & Primary & $\begin{array}{l}\text { non-absorbable } \\
\text { suture }\end{array}$ & NS (yes?) & No & bronchitis & 6 weeks \\
\hline 22 & Mirza [10] & 2011 & M & 65 & Yes & Yes & $\mathrm{L}$ & $6 / 8$ & - & Cough & Patch & $\begin{array}{l}\text { soft prosthetic } \\
\text { patch }\end{array}$ & - & No & COPD & - \\
\hline 23 & O’Shea [11] & 2012 & $\mathrm{~F}$ & 40 & - & - & $\mathrm{R}$ & $9 / 10$ & - & Cough & - & - & - & Yes & asthma & 3 months \\
\hline 24 & present case & 2012 & M & 60 & Yes & Yes & $\mathrm{L}$ & $8 / 9$ & 10 & Cough & Patch & $\begin{array}{c}\text { absorbable } \\
\text { mesh/suture }\end{array}$ & Yes & Yes & COPD & $\begin{array}{c}5 \text { months } \\
\text { rec }\end{array}$ \\
\hline
\end{tabular}

ICS: intercostal space; COPD: chronic obstructive pulmonary disease. 
one was female. Herniation involved the lower 7th to 9 th intercostal spaces in $88 \%$ of patients (21/24); this region lacks muscular support for the chest wall provided by the trapezius, latissimus dorsi, rhomboid, and especially the external intercostal muscles [7] [8]. Nine patients (38\%) were obese, 13 (54\%) had a history of smoking, and $18(75 \%)$ a history of pulmonary disease such as COPD, asthma, pneumonia, or bronchitis; these are also potential contributors to increased intrathoracic pressure. Lung herniation occurred with equal frequency on the right and left sides. The hernia sizes ranged from 3 to $30 \mathrm{~cm}$ with a median of $11 \mathrm{~cm}$.

Information regarding therapy was provided in 19 cases. Only two patients presented with subcutaneous emphysema/pneumothorax, including our case [11]. Eighteen of 19 patients (95\%) underwent surgical repair (including three emergency operations [8] [9]), and only one patient was treated non-operatively with a compressive pad [5]. Primary surgical repair was performed in nine patients, and the others underwent patch closure methods. In 9 patients who have been followed up for more than 3 months (range, 3 months to 5 years; median, 1 year), the lung hernia recurred in two patients [6], and abdominal wall herniation developed in one [7]. Important to note, there was no recurrence in patients who underwent surgical repair using wire or non-absorbable mesh.

Surgical management should be individualized to each patient, as previously mentioned [1]. Although newly described fixation techniques using laminar hooks connected to titanium bars [12], a soft prosthetic patch [10], or non-absorbable mesh [2] [4] [6] [8] have been documented, they involved elective surgical procedures, which have a lower risk of infection. As a result, we decided to perform emergency surgical repair and did not use any non-absorbable materials to avoid the development of a secondary infection site.

\section{Conclusion}

The use of absorbable materials may not be recommended for repair of cough/sneeze-induced lung herniation with the exception of patients at high risk of infection.

\section{Conflict of Interest Statement}

The authors report no conflicts of interest.

\section{References}

[1] Weissberg, D. and Refaely, Y (2002) Hernia of the Lung. The Annals of Thoracic Surgery, 74, 1963-1966. http://dx.doi.org/10.1016/S0003-4975(02)04077-8

[2] Ross, R.T. and Burnett, C.M. (1999) Atraumatic Lung Hernia. The Annals of Thoracic Surgery, 67, 1496-1497. http://dx.doi.org/10.1016/S0003-4975(99)00225-8

[3] Goverde, P., Van Schil, P., Van den Brande, F. and Vanmaele, R. (1998) Chronic Herniation of the Lung in a Patient with Chronic Obstructive Pulmonary Disease. Case Report and Review of the Literature. The Thoracic and Cardiovascular Surgeon, 46, 164-166. http://dx.doi.org/10.1055/s-2007-1010219

[4] Brock, M.V. and Heitmiller, R.F. (2000) Spontaneous Anterior Thoracic Lung Hernias. The Journal of Thoracic and Cardiovascular Surgery, 119, 1046-1047. http://dx.doi.org/10.1016/S0022-5223(00)70103-6

[5] Tack, D., Wattiez, A., Schtickzelle, J.C. and Delcour, C. (2000) Spontaneous Lung Herniation after a Single Cough. European Radiology, 10, 500-502. http://dx.doi.org/10.1007/s003300050084

[6] Szentkereszty, Z., Boros, M., Sápy, P. and Kiss, S.S. (2006) Surgical Treatment of Intercostal Hernia with Implantation of Polypropylene Mesh. Hernia, 10, 354-356. http://dx.doi.org/10.1007/s10029-005-0035-5

[7] Sulaiman, A., Cottin, V., De Souza Neto, E.P., et al. (2006) Cough-Induced Intercostal Lung Herniation Requiring Surgery: Report of A Case. Surgery Today, 36, 978-980. http://dx.doi.org/10.1007/s00595-006-3284-8

[8] Jastrow, K.M., Chu, D., Jaroszewski, D., et al. (2009) Posterior Lung Herniation after a Coughing Spell: A Case Report. Cases Journal, 2, 86. http://dx.doi.org/10.1186/1757-1626-2-86

[9] Shankar, S. and Abbas, A. (2010) Acute Respiratory Failure Caused by Spontaneous Herniation of the Lung. The Ochsner Journal, 10, 256-258.

[10] Mirza, A., Gogna, R., Kumaran, M., Malik, M. and Martin-Ucar, A.E. (2011) The Surgical Management of Intercostal Lung Herniation Using Bioprosthesis. Journal of Surgical Case Reports, 2, 6.

[11] O’Shea, M. and Cleasby, M. (2012) Images in Clinical Medicine. Lung Herniation after Cough-Induced Rupture of Intercostal Muscle. The New England Journal of Medicine, 366, 74. http://dx.doi.org/10.1056/NEJMicm1106070

[12] Wiens, S., Hunt, I., Mahood, J., et al. (2009) Novel Fixation Technique for the Surgical Repair of Lung Hernias. The Annals of Thoracic Surgery, 88, 1034-1035. http://dx.doi.org/10.1016/j.athoracsur.2008.12.032 